\title{
Decline of childhood overweight and obesity in Italy from 2008 to 2016: results from 5 rounds of the population-based surveillance system
}

\author{
Laura Lauria*iD, Angela Spinelli, Marta Buoncristiano and Paola Nardone
}

\begin{abstract}
Background: Given the effects of childhood obesity on future health, and the lack of information of its prevalence in Italy, a national surveillance system was implemented in 2007. It is OKkio alla SALUTE, part of the WHO/Europe Childhood Obesity Surveillance Initiative (COSI). This study reports the 2008-2016 trends by sex, area of residence and socio-demographic characteristics in the prevalence of overweight and obesity in primary school children (8-9 years).
\end{abstract}

Methods: In each round of the surveillance held in 2008, 2010, 2012, 2014 and 2016, a nationally representative sample of about 45,000 children, was weighed and measured with standard equipment and methods by trained personnel. Children were classified as normal weight, overweight or obese using World Obesity Federation (WOF) (formerly the International Obesity Task Force (IOTF)) and WHO cut-offs. Children's sex, area of residence and mothers' education and citizenship, were obtained using self-reported questionnaires and were assessed using multivariate logistic regression models.

Results: Between 2008 and 2016, the overall prevalence of obesity dropped from 12.0 to 9.3\% (WOF-IOTF) and from 21.2 to $17.0 \%(\mathrm{WHO})$, while the overall prevalence of overweight (including obesity) from 35.2 to 30.6\% (WOFIOTF) and from 44.4 to $39.4 \%$ (WHO). Reduction in the prevalence of overweight and obesity was greater in boys $(-14.5 \%$, $p$ for trend $<0.001$; and $-24.7 \%, p=0.001)$ compared to girls $(-11.1 \%, p<0.001$; and $-19.2 \%, p=0.034)$. Decreasing trends were observed in overweight prevalences within children resident in the center and in the south. Decreasing trends in obesity prevalences were observed among boys resident in the north and in the south, and among girls resident in the center. Decreasing trends were observed in overweight prevalences within sociodemographic characteristics, except among children with low educated and foreign mothers; and in obesity prevalences for children with medium educated mothers, and girls with Italian mothers.

Conclusions: From 2008 to 2016 a decrease of childhood overweight and obesity was observed in Italy. However, as these prevalences are still among the highest in Europe, there is need to continue their monitoring and implement more interventions to promote healthy lifestyles. More effort should be focused on children belonging to low social classes.

Keywords: Prevalence trends, Children, Overweight, Obesity, Socio-demographic characteristics, Italy

\footnotetext{
* Correspondence: laura.lauria@iss.it

National Centre for Disease Prevention and Health Promotion, National

Institute of Health, Viale Regina Elena 299, 00161 Rome, Italy
}

(c) The Author(s). 2019 Open Access This article is distributed under the terms of the Creative Commons Attribution 4.0 International License (http://creativecommons.org/licenses/by/4.0/), which permits unrestricted use, distribution, and reproduction in any medium, provided you give appropriate credit to the original author(s) and the source, provide a link to the Creative Commons license, and indicate if changes were made. The Creative Commons Public Domain Dedication waiver (http://creativecommons.org/publicdomain/zero/1.0/) applies to the data made available in this article, unless otherwise stated. 


\section{Background}

Childhood overweight and obesity have increased dramatically during the past decades, both in developing and developed countries and this presents one of the most serious public health challenges of the 21st century [1-3]. Although in recent years, the scientific literature suggests that the overall prevalence of paediatric obesity in developed countries may have plateaued [4], the prevalence of severe obesity is increasing $[5,6]$.

Childhood obesity is often persistent and increases the likelihood of lifelong health problems $[7,8]$ including cardiovascular disease, diabetes, musculoskeletal disorders, dyslipidemia, non-alcoholic fatty liver disease (NAFLD), hypertension and psychological problems [913]. Children who are overweight by kindergarten have a 4-fold greater risk of being obese in adolescence and obesity rates increase as children grow older, in particular when they become adolescents [14, 15].

A variety of factors have been found to be associated with obesity including sex, age, socioeconomic status, racial/ethnic groups, and geographic regions [16]. Boys have been found to be at greater risk of being obese than girls [17], but sex differences may vary by race/ethnicity as shown in a study on severe obesity in which Hispanic boys and non-Hispanic black girls had the highest prevalence of severe obesity [18]. Immigrant children and those of ethnic minorities are at higher risk of childhood obesity than native-born children [19].

Overweight rates are higher for children growing up in families with low income than for children from high income families [20]. Social disparities in obesity persist and are growing in some countries [21]. Socio-economic variability in childhood obesity and related lifestyles have also been reported in Italy [22] where the prevalence is lower in the north and higher in southern regions where socio-economic conditions and other health indicators are worst [23].

Varying cultural norms in feeding practices are also associated with children's weight $[24,25]$, though this can be confounded by education and economic status.

Since 2007, following the recommendations of the WHO European Ministerial Conference on Counteracting Obesity [26], the Italian Minister of Health has promoted and funded the National Nutritional Surveillance System called "OKkio alla SALUTE" [27, 28]. The objective of this is to obtain information on nutritional status by routine measurement of bodyweight, height and lifestyle behaviour among primary-school children. This surveillance is part of the Childhood Obesity Surveillance Initiative (COSI) of the WHO Regional Office for Europe, which enables comparisons to be made between countries within the European Region [29].

The aim of this study was to examine the trends in the prevalence of overweight and obesity among primary school children (aged 8-9 years) from 2008/9 to 2016 using the WHO $[30,31]$ and World Obesity Federation (formerly International Obesity Task Force) WOF-IOTF $[32,33]$ cut-off values. Having obtained similar results with the two reference systems, further analysis of sex, geographical area of residence, mother's educational level and citizenship used the WOF-IOTF definitions.

\section{Methods}

The first data collection of the Italian National Surveillance System "OKkio alla SALUTE", coordinated by the National Institute of Health (Istituto Superiore di Sanità), was in 2008 [34]. After, there were another four rounds in 2010 [35], 2012 [36], 2014 [37, 38] and 2016 [39]. The target population was children in the third grade of all primary schools, who are almost all 8 or 9 years old. At each round, with the support and assistance of the Ministry of Education, Universities and Research, lists of public and private schools and classes with the number of children in each class were obtained from regional school authorities. A stratified cluster sample design was used, following World Health Organization cluster survey methodology [40], with classes as the sampling unit. All children of the selected classes were invited to participate. All 21 Italian regions took part with representative samples at regional level or, if specifically requested, at Local Health Units (LHU) level were taken. Sample size was estimated in such a way as to achieve a precision of $3 \%$ in the estimate of the body mass index (BMI) for a regional estimates and of $5 \%$ for a LHU estimates. The finite population correction was used because the sample size was large relative to the school children population size, in particular when LHU estimates were made. The sample size estimate was also adjusted by assuming a design effect of 2 at the first round of data collection to take into account of the complex cluster sampling design. The value of the design effect found in two preliminary pilot studies for the BMI was very close to the unity; but we assumed a value of 2 to take account of other variables measured with the questionnaire which have assumed values up to about 3. The design-effect in each of the subsequent data collection cycles was estimated for each area of the country based on the results of the previous round. The value of the design effect for the BMI is variable among LHU or regions but almost always its value is no higher than 2 .

According to the COSI protocol, children were weighed and measured with standard equipment (New Seca 872 TM scales and Seca 214 stadiometers. Seca $\mathrm{GmbH} \&$ co. Hamburg, Germany) and standard methods by trained local health staff. Children were weighed and measured after removing heavy clothing, and a simple checklist was used to describe the type of 
clothing that the child was wearing (the average weight of each type of clothing was used to adjust the measured weight for the analysis) [41]. Body Mass Index (BMI) was calculated and, according to the sex-specific WOF-IOTF cut-offs [32, 33], children were classified as overweight or obese. To facilitate international comparisons, the prevalences of overweight and obesity were also estimated using the WHO cut-off points [30, 31].

Children and their parents also completed two brief questionnaires. In the questionnaire addressed to the parents, information on their education (in 2008/9 this information was collected only with reference to the respondent parent) and nationality (not collected in 2008/ 9) was asked. The information from the two questionnaires was then linked through a unique identification code.

The questionnaires were available in Italian and nine other languages. The protocol was approved by the Institutional Ethical Board of the National Institute of Health and included the use of opt-out consent; that is parents were asked to specifically refuse participation, but the lack of a returned form was taken to imply consent to their child's participation. Prevalences of overweight (defined as including obesity if not otherwise specified) and of obesity were the main outcome variables. The explanatory variables used for the analysis were: sex (males, females), area of residence (north, center, south), mother's education (low = less than high school, medium $=$ high school, high $=$ university degree or more), citizenship (Italian, foreign). Differences in the prevalence according to these socio-demographic characteristics were tested by the Pearson design-based $X$ [2]. Weighted prevalences of overweight and obesity, with their $95 \%$ confidence intervals stratified by sex, were calculated for all the socio-demographic variables. Changes in the prevalence of overweight and obesity across the period 2008/9-2016 have been assessed using multivariate logistic regression analyses, taking account of the complex sample survey design. For each outcome of interest, a multivariate logistic model included the information about round of data collection as a categorical covariate. However, to investigate the linear time trend in the prevalence of overweight and obesity, multivariate logistic regression models were estimated that included a linear term for time, as well as all the socio-demographic variables. The significance of the trend was assessed using an adjusted Wald $F$ test with $\alpha$ $=0.05$. Separate models were used to test linear trends in prevalences by each stratification variable. Weights to adjust for the sampling design, oversampling and non-response were calculated and used to infer the results from the sample to the population. Moreover, all analyses took account of the effect of the complex survey design - namely clustering and stratification - on the estimation of the standard errors which were used to calculate the 95\% confidence intervals. Data were analyzed using Stata statistical software version 11.

\section{Results}

The surveys involved about 45,000 children in each of the five rounds. About 3\% of the parents refused authorization for the participation of their child. Sixty-six percent of the children were 8 years-old and $51 \%$ male. Forty-five percent were resident in the North of Italy, $22 \%$ in the Center and $33 \%$ in the South. Twenty-eight percent of the children had mothers with a low level of education, $48 \%$ medium level and $24 \%$ high educational level. Thirteen percent of mothers were foreign citizens. Figure 1 shows the time trends of WHO and WOF-IOTF estimates of the prevalence of overweight (including obesity) and obesity among 8-9 aged children. The different definitions of the cut-off mainly affect the prevalences of obesity, with WHO estimates 7-9 percentage points higher than WOF-IOTF estimates, almost the same difference is seen in the estimates of overweight. Between 2008/9 and 2016, the prevalence of overweight according to WHO, decreased from 44.4 to $39.4 \%$ (a relative change of $11.3 \%$, p for trend $<0.001$ ) and according to WOF-IOTF from 35.2 to $30.6 \%(-13.1 \%, \mathrm{p}$ for trend $<0.001)$. Obesity decreased from 21.2 to $17.0 \%(-19.8 \%, \mathrm{p}$ for trend $<0.001)$ and from 12.0 to $9.3 \%(-22.5 \%$, $\mathrm{p}$ for trend $<0.001)$ respectively. The WHO and WOF-IOTF prevalences of overweight not including obesity show a reduction from 23.2 to $22.4 \%(-3.4 \%, \mathrm{p}$ for trend $=0.01)$ and from 23.2 to $21.3 \% \quad(-8.2 \%, \quad \mathrm{p}$ for trend $<0.001)$ respectively. Subsequent analyses are based on WOF-IOTF estimates. Table 1 shows the time trends of the odds ratios for overweight and obesity controlling for the child's age, sex and residence, and for mother's education. The tests for the linear trend of overweight and of obesity are both statistically significant, $p<0.001$.

The odds ratios by survey round show a similar but not always significant reduction of overweight and of obesity in 2010 and 2012 with respect to the reference round of 2008/9. The odds ratios are more marked in the last two rounds of data collection, in particular those regarding obesity. Moreover, the odds ratio and 95\% confidence interval for overweight in the last round of 2016 are similar to the 2014 values, which may imply that a significant reduction in overweight occurred from 2008 to 2014 but little change occurred in the subsequent period.

\section{Overweight children}

Table 2 shows prevalences of overweight by sex and socio-demographic characteristics. All prevalences show 


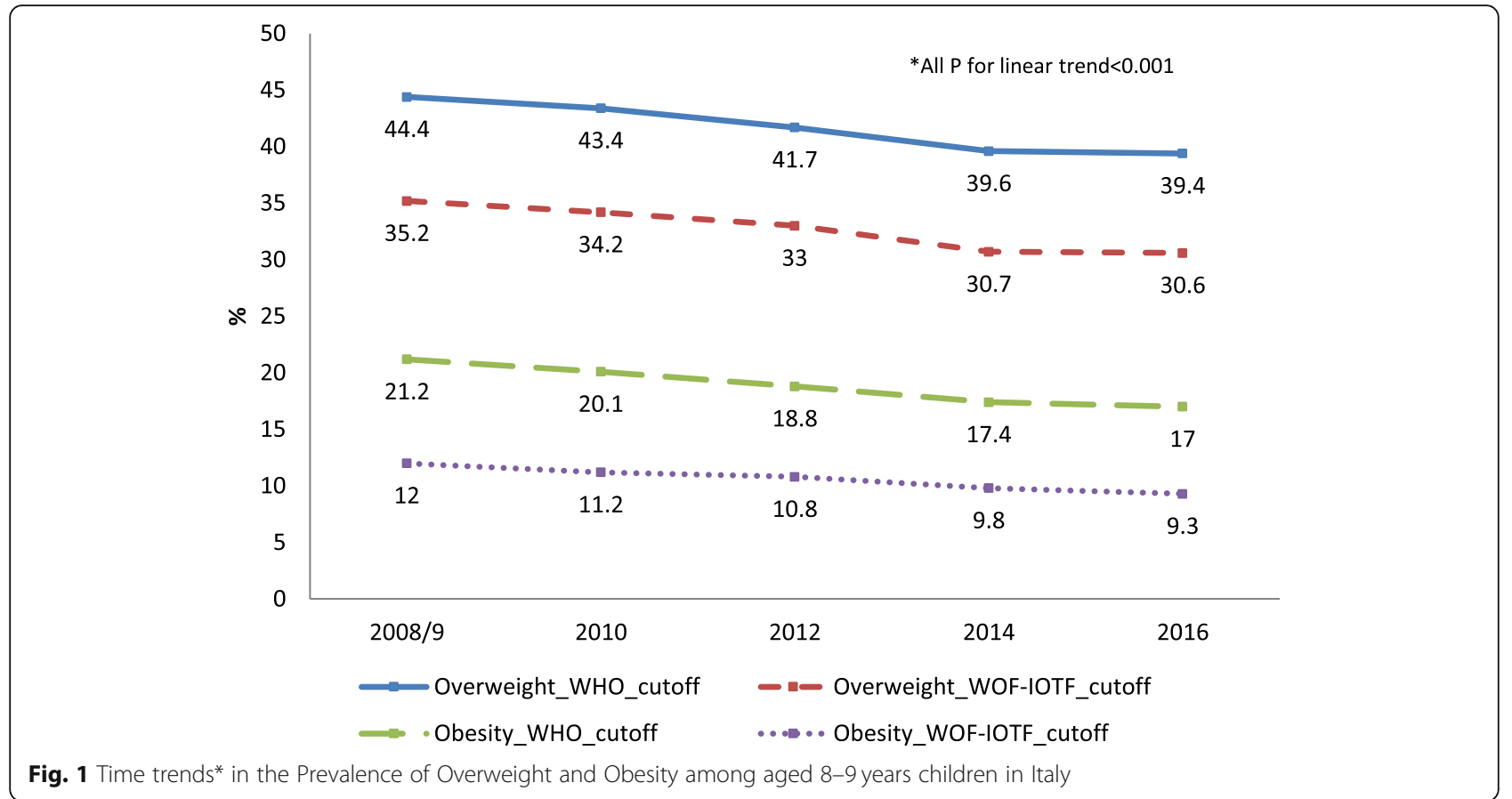

a decreasing trend between 2008 and 2016 except those related to children of foreign mothers.

The overall prevalence of overweight among boys across the 2008/9-2016 period shows a relative reduction of $14.5 \%$ (from 35.9 to $30.7 \%, p$ for trend $=0.001$ ). Likewise, the overall prevalence of overweight among girls shows a relative reduction of $11.1 \%$ (from 34.3 to $30.5 \%$, p for trend $<0.001$ ). For boys, a statistically significant decreasing linear trend is observed for those resident in the center $(p=0.001)$ or in the south $(p<0.001)$, for those with a medium educated mothers $(p<0.001)$ or with a higher education $(p=0.002)$, and with

Table 1 Multivariate analysis of overweight and obesity trends ${ }^{a}$

\begin{tabular}{|c|c|c|c|c|c|c|c|}
\hline & \multirow[t]{2}{*}{$n$} & \multicolumn{3}{|c|}{ Overweight } & \multicolumn{3}{|c|}{ Obesity } \\
\hline & & $\overline{\mathrm{OR}}$ & $95 \% \mathrm{Cl}$ & $P$ value & $\overline{\mathrm{OR}}$ & $95 \% \mathrm{Cl}$ & $P$ value \\
\hline \multicolumn{8}{|c|}{ Year of data collection } \\
\hline 2008/9 & 47,254 & 1 & & & 1 & & \\
\hline 2010 & 41,595 & 0.97 & $0.93-1.00$ & 0.106 & 0.94 & $0.88-1.00$ & 0.037 \\
\hline 2012 & 45,421 & 0.96 & $0.92-1.00$ & 0.037 & 0.96 & $0.90-1.02$ & 0.185 \\
\hline 2014 & 47,317 & 0.90 & $0.86-0.94$ & $<0.001$ & 0.92 & $0.86-0.99$ & 0.015 \\
\hline 2016 & 44,193 & 0.90 & $0.86-0.94$ & $<0.001$ & 0.88 & $0.82-0.94$ & $<0.001$ \\
\hline
\end{tabular}

Linear trend over the period 2008-2016

$225,780 \quad 0.97 \quad 0.96-0.98<0.001 \quad 0.97 \quad 0.96-0.99<0.001$

${ }^{a}$ Results represent logistic regression for complex survey data of the 5 rounds of "OKkio alla SALUTE" with reference to $2008 / 9$ as well as results examining the time round as an ordinal variable controlling for children's age and sex and for mother's education and area of residence
Italian mothers $(p<0.001)$. For boys born to foreign mothers, the trend is statistically significant but increasing $(p=0.029)$.

For girls, a statistically significant decreasing linear trend is observed for those resident in the center $(p=0.016)$ and in the south $(p=0.002)$, for those whose mothers have a medium level of education $(p=0.002)$ and, although borderline, a higher level of education $(p=0.051)$, and were Italian $(p<0.001)$.

\section{Obese children}

Table 3 shows prevalences of obesity by sex and socio-demographic characteristics. All trends are negative, except that of children born to foreign mothers for which no trend was detected.

The overall prevalence of obesity among boys across the 2008/9-2016 period shows a relative reduction of $24.7 \%$ (from 12.9 to $9.7 \%$, p for trend $=0.001$ ). Likewise, the overall prevalence of obesity among girls across the considered period shows a relative reduction of $19.2 \%$ (from 10.9 to $8.8 \%$, p for trend $=0.034$ ). For boys, a statistically significant decreasing linear trend can also be observed for those resident in the north $(p=0.042)$ and in the south of the country $(p=0.017)$, and for those whose mothers have a medium level of education $(p=0.005)$. A borderline statistical significance was observed for boys whose mothers are Italian $(p=0.061)$.

For girls, there is a statistically significant decreasing linear trend for those resident in the center $(p=0.028)$, 
Table 2 Prevalence of overweight (including obesity) among primary school children from 2008 to 2016 stratified by gender and maternal characteristics

\begin{tabular}{|c|c|c|c|c|c|c|c|}
\hline \multirow{3}{*}{ Prevalenc } & \multirow{2}{*}{$\begin{array}{l}2008 / 9 \\
\%(95 \% \mathrm{Cl}) \\
\end{array}$} & \multirow{2}{*}{$\begin{array}{l}2010 \\
\%(95 \% \mathrm{Cl}) \\
\end{array}$} & \multirow{2}{*}{$\begin{array}{l}2012 \\
\%(95 \% \mathrm{Cl})\end{array}$} & \multirow{2}{*}{$\begin{array}{l}2014 \\
\%(95 \% \mathrm{Cl}) \\
\end{array}$} & \multirow{2}{*}{$\begin{array}{l}2016 \\
\%(95 \% \mathrm{Cl}) \\
\end{array}$} & \multirow{2}{*}{$\begin{array}{l}\text { Relative change } \\
2016 \text { vs 2008/9 } \\
\%\end{array}$} & \multirow[t]{2}{*}{$\begin{array}{l}P \text { value for linear } \\
\text { trend }\end{array}$} \\
\hline & & & & & & & \\
\hline & & & & & & & \\
\hline Boys & $35.9[35.1-36.8]$ & $34.6[33.8-35.5]$ & $33.1[32.3-33.9]$ & $31.0[30.2-31.8]$ & $30.7[29.8-31.6]$ & -14.5 & $<0.001$ \\
\hline Girls & $34.3[33.4-35.2]$ & $33.7[32.9-34.6]$ & $32.4[31.6-33.3]$ & $30.5[29.7-31.4]$ & $30.5[29.6-31.4]$ & -11.1 & $<0.001$ \\
\hline \multicolumn{8}{|c|}{ Area of residence } \\
\hline \multicolumn{8}{|l|}{ North } \\
\hline Boys & 27.6 [26.2-28.9] & $27.1[26.0-28.1]$ & $26.7[25.5-27.9]$ & $24.9[23.6-26.3]$ & $25.1[23.7-26.6]$ & -9.1 & 0.085 \\
\hline Girls & $25.7[24.4-27.0]$ & $26.9[25.9-28.0]$ & $26.2[24.9-27.6]$ & $24.5[23.2-25.8]$ & $25.4[24.0-26.8]$ & -1.2 & 0.461 \\
\hline \multicolumn{8}{|l|}{ Center } \\
\hline Boys & $33.7[31.9-35.4]$ & $32.5[31-34.1]$ & $31.4[29.6-33.2]$ & $29.6[28.1-31.2]$ & $29.5[27.7-31.4]$ & -12.5 & 0.001 \\
\hline Girls & $33.6[31.7-35.6]$ & $31.4[29.8-33.0]$ & $29.5[27.8-31.3]$ & $29.3[27.7-30.8]$ & $29.9[28.0-31.8]$ & -11.0 & 0.016 \\
\hline \multicolumn{8}{|l|}{ South } \\
\hline Boys & $44.2[42.8-45.6]$ & $42.8[41.1-44.4]$ & $42.5[41.2-43.7]$ & $41.1[39.8-42.4]$ & $39.5[38.3-40.7]$ & -10.6 & $<0.001$ \\
\hline Girls & $41.9[40.4-43.4]$ & $41.3[39.7-42.8]$ & $42.4[41.2-43.7]$ & 40.5 [39.1-41.9] & $37.8[36.5-39.1]$ & -9.8 & 0.002 \\
\hline \multicolumn{8}{|c|}{ Mother's educational level } \\
\hline \multicolumn{8}{|l|}{ Low } \\
\hline Boys & $39.2[37.8-40.7]$ & $37.3[35.9-38.6]$ & 37.9 [36.6-39.2] & $35.9[34.4-37.4]$ & $36.7[35.2-38.3]$ & -6.4 & 0.212 \\
\hline Girls & $38.4[36.9-40.0]$ & $36.7[35.3-38.2]$ & 36.9 [35.5-38.3] & 35.3 [33.8-36.9] & $36.1[34.5-37.6]$ & -6.0 & 0.286 \\
\hline \multicolumn{8}{|c|}{ Medium } \\
\hline Boys & 35.6 [34.2-37.0] & 33.7 [32.5-34.9] & 32.6 [31.5-33.7] & 30.6 [29.4-31.8] & $29.9[28.7-31.2]$ & -16.0 & $<0.001$ \\
\hline Girls & $33.2[31.7-34.6]$ & 33 [31.9-34.2] & $31.3[30.1-32.5]$ & 30.4 [29.2-31.6] & 29.7 [28.4-30.9] & -10.5 & 0.002 \\
\hline \multicolumn{8}{|l|}{ High } \\
\hline Boys & 30.3 [28.0-32.7] & 30.0 [28.0-32.0] & 25.0 [23.3-26.8] & $24.8[23.3-26.3$ & $25.8[24.3-27.4]$ & -14.9 & 0.002 \\
\hline Girls & 26.5 [24.5-28.6] & 27.9 [26.1-29.8] & $25.6[23.9-27.4]$ & $23.1[21.5-24.7]$ & 24.6 [22.9-26.4] & -7.2 & 0.051 \\
\hline \multicolumn{8}{|c|}{ Mother's citizenship ${ }^{a}$} \\
\hline \multicolumn{8}{|l|}{ Italian } \\
\hline Boy & - & $34.9[34.0-35.8]$ & $33.4[32.6-34.2]$ & 30.9 [30.0-31.8] & $30.2[29.2-31.1]$ & -13.5 & $<0.001$ \\
\hline Girls & - & $34.3[33.4-35.2]$ & $32.6[31.7-33.4]$ & 30.9 [30.0-31.8] & 30.5 [29.6-31.5] & -11.1 & 0.002 \\
\hline \multicolumn{8}{|l|}{ Foreign } \\
\hline Boys & - & $31.1[28.8-33.4]$ & 31.0 [28.9-33.2] & 31.5 [29.4-33.7] & $34.4[31.8-37.1]$ & +10.6 & 0.029 \\
\hline Girls & - & $27.9[25.8-30.2]$ & $29.5[27.1-32.1]$ & 27.1 [25.1-29.3] & $29.2[27.0-31.4]$ & +4.7 & 0.825 \\
\hline
\end{tabular}

Information about mother's citizenship was not gathered in 2008/9

for those whose mothers have a medium level of education $(p=0.014)$ and Italian citizenship $(p=0.05)$.

The observed small reductions in prevalences of obesity, if interpreted as probabilities and transformed into corresponding absolute numbers of children throughout the Italian population aged 8-9 years, become very substantial. As an example, applying the WOF-IOTF prevalence of obesity in the 2008/9 (12\%) and 2016 (9.3\%) to the whole population aged 8-9 years resident in Italy in $2016(N=1,147,558)$, implies a reduction of about 31,000 obese children.

\section{Discussion}

Our study provides evidence of a slight but persistent reduction of overweight and obesity in 8-9 year old children across the 2008/9-2016 period in Italy. The estimates are based on large nationally representative samples distributed by socio-economic characteristics similar to that observed in the general population of pupils attending Italian primary schools. The estimated reduction in the number of obese children aged 8-9 years in Italy is 31,000 . If this percent reduction were the same in children of all ages (6-10 years) in Italian primary 
Table 3 Prevalence of obesity among primary school children from 2008 to 2016 stratified by gender and maternal characteristics

\begin{tabular}{|c|c|c|c|c|c|c|c|}
\hline & $2008 / 9$ & 2010 & 2012 & 2014 & 2016 & $\begin{array}{l}\text { Relative change } \\
2016 \text { vs 2008/9 }\end{array}$ & $\begin{array}{l}P \text { value for linear } \\
\text { trend }\end{array}$ \\
\hline & $\%(95 \% \mathrm{Cl})$ & $\%(95 \% \mathrm{Cl})$ & $\%(95 \% \mathrm{Cl})$ & $\%(95 \% \mathrm{Cl})$ & $\%(95 \% \mathrm{Cl})$ & $\%$ & \\
\hline Prevalen & & & & & & & \\
\hline Boys & $12.9[12.3-13.5]$ & $11.8[11.2-12.3]$ & $10.9[10.5-11.4]$ & $10.3[9.76-10.8]$ & 9.7 [9.2-10.2] & -24.7 & 0.001 \\
\hline Girls & 10.9 [10.4-11.5] & 10.5 [9.9-11.1] & 10.2 [9.7-10.8] & 9.4 [8.9-9.9] & 8.8 [8.3-9.3] & -19.2 & 0.034 \\
\hline Area of & idence & & & & & & \\
\hline North & & & & & & & \\
\hline Boys & 7.6 [6.9-8.3] & $7.9[7.3-8.5]$ & 7.0 [6.3-7.6] & $7.1[6.4-7.9]$ & $6.0[5.3-6.7]$ & -21.4 & 0.042 \\
\hline Girls & $6.5[5.7-7.4]$ & $6.8[6.2-7.3]$ & $6.3[5.6-7.0]$ & $6.2[5.6-6.8]$ & $5.9[5.2-6.7]$ & -9.5 & 0.672 \\
\hline Center & & & & & & & \\
\hline Boys & 10.8 [9.6-12.1] & 9.6 [8.6-10.7] & 8.8 [7.9-9.9] & 8.9 [8.0-9.9] & 9.1 [8.1-10.3] & -15.6 & 0.235 \\
\hline Girls & 8.9 [7.8-10.2] & $8.6[7.6-9.7]$ & 8.7 [7.5-9.9] & 8.0 [7.0-9.1] & $7.0[6.2-8.0]$ & -21.5 & 0.028 \\
\hline South & & & & & & & \\
\hline Boys & 18.5 [17.4-19.6] & 16.7 [15.5-17.8] & 17.4 [16.5-18.3] & 16.0 [15.0-17.0] & 15.5 [14.6-16.5] & -16.2 & 0.017 \\
\hline Girls & $15.7[14.7-16.8]$ & $15.0[13.8-16.2]$ & $16.4[15.4-17.4]$ & $15.1[14.0-16.1]$ & 13.8 [13.0-14.7] & -12.1 & 0.172 \\
\hline Mother's & ducational level & & & & & & \\
\hline Low & & & & & & & \\
\hline Boys & 16.7 [15.7-17.9] & 14.6 [13.6-15.6] & 14.6 [13.7-15.5] & 14.9 [13.8-16] & 13.8 [12.6-14.9] & -17.4 & 0.141 \\
\hline Girls & $14.4[13.3-15.5]$ & $13.3[12.3-14.4]$ & $14.1[13.2-15.1]$ & 13.4 [12.3-14.5] & $12.6[11.6-13.7]$ & -12.5 & 0.443 \\
\hline Medium & & & & & & & \\
\hline Boys & 11.2 [10.3-12.0] & 10.6 [9.8-11.5] & 10.0 [9.3-10.7] & 9.2 [8.4-9.9] & 9.1 [8.4-9.8] & -19.0 & 0.005 \\
\hline Girls & 9.8 [8.9-10.7] & 9.5 [8.8-10.4] & 9.0 [8.3-9.8] & 8.3 [7.7-9.0] & 8.2 [7.5-8.9] & -16.3 & 0.014 \\
\hline High & & & & & & & \\
\hline Boys & 8.1 [6.8-9.7] & $6.7[5.7-7.8]$ & $5.6[4.8-6.4]$ & $5.4[4.7-6.1]$ & $6.2[5.4-7.0]$ & -24.4 & 0.096 \\
\hline Girls & $5.0[4.0-6.2]$ & $5.8[4.8-6.9]$ & $5.4[4.5-6.3]$ & $5.1[4.3-6.0]$ & $4.8[4.1-5.6]$ & -3.6 & 0.912 \\
\hline Mother's & tizenship ${ }^{a}$ & & & & & & \\
\hline Italian & & & & & & & \\
\hline Boys & - & $11.6[11.0-12.2]$ & $11.1[10.5-11.6]$ & 10.1 [9.5-10.6] & 9.4 [8.9-10.0] & -18.7 & 0.061 \\
\hline Girls & - & $10.8[10.2-11.4]$ & 10.3 [9.7-10.8] & 9.4 [8.9-10.0] & 8.9 [8.4-9.4] & -17.8 & 0.05 \\
\hline Foreign & & & & & & & \\
\hline Boys & - & 10.5 [9.0-12.1] & $9.3[8.0-10.7]$ & $10.7[9.2-12.4]$ & $10.5[9.1-12.2]$ & 0.0 & 0.354 \\
\hline Girls & & $7.4[6.1-8.8]$ & $8.5[7.1-10.2]$ & 7.7 [6.6-9.1] & 7.8 [6.5-9.2] & 5.3 & 0.881 \\
\hline
\end{tabular}

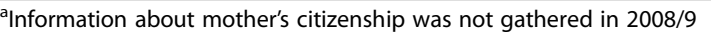

schools, the total reduction would be of the order of 15,000 children for each year of age. If the causes of the reduction were interventions of health promotion, information campaigns, etc., which are addressed to all primary school children (aged 6-10years), this crude estimate may be plausible.

One objective of the monitoring of children's weight is to increase the general awareness of the problem of overweight and obesity in primary school children and to promote interventions. In the past few years, several public events have been organized and media articles published to increase awareness of obesity and stress the importance of healthy lifestyle in Italy. Moreover, numerous interventions promoting healthy lifestyles, such as increasing physical activity and improving eating habits in the schools, have been implemented at regional and local level $[36,42]$.

The prevalences of overweight and of obesity among boys are higher than among girls across all the survey rounds, as is observed in most European countries [17], but the differences have diminished over time and are minimal in the 2016 round.

The stratified analyses of the prevalence of both overweight and obesity by socio-demographic characteristics show, from 2008/9 to 2016, reductions except for children of foreign mothers. Thus, children of foreign 
mothers, who had lower overweight and obesity prevalences in 2010, are comparable to children of Italian mothers in the last round 2016. This could be an indication of the cultural integration of the foreign children and families, which includes changes in their lifestyle and consequent higher risk of overweight and obesity.

The results regarding mother's education deserve more consideration. The prevalences of overweight and of obesity are always higher for children of mothers with lower education and they do not show a statistically significant decreasing trend. The prevalences of obesity in children of low educated mothers are two-three times those of highly educated mothers. This implies persisting socioeconomic disparity in overweight and obesity and confirms the impact of parental education, as has been found by others [43].

Although in the last decade, policies and activities to reduce childhood obesity in Italy seem to have been effective, addressing the social determinants of health to move towards equity has only been marginally effective and important differences still exist. In part, this may be due to the fact that for socio-economically disadvantaged people, it may be more difficult to change unhealthy behaviours because their environment offers fewer opportunities and because it is more expensive to eat healthy foods $[44,45]$.

The prevalence of overweight and obesity is always higher in the south, the more economically disadvantaged part of the country, compared with the center and the north, although the reducing trends seem to slightly reduce these differentials. In our country, these geographic differences in the prevalence of overweight and obesity have also been found in the adolescent population [46]. For example, the WOF-IOTF prevalences of overweight (excluding obesity) among adolescents aged 11 years were: boys $14.5,21.3,28.5 \%$; girls $11.6,13.5,21.1 \%$ in the north, center and south of the country respectively.

Both the overall high prevalence and the geographic disparities have profound implications for the country's healthcare system now and in the future [47].

This study has some limitations. We have not considered important predictors of overweight and obesity in children, such as maternal BMI, which is correlated with children's BMI and could be a confounder of the relationship between children BMI and the other socio-demographic factors considered in this study. We have performed many statistical tests without applying the Bonferroni correction. Results that are marginally statistically significant should be interpreted with caution.

The main strengths of this study are the representative population sample of school children throughout the country with more than 40,000 children and parents included in each survey and the use of standardized measurements of children's weight and height. This large sample size allows stratified trends according to socio-economic characteristics to be investigated separately for males and females.

In this study, the overall prevalences of overweight and obesity based on the different WHO and WOF-IOTF cut-off criteria were calculated. Although some values, especially those related to obesity, show a big difference, with the WHO prevalence being 8-9 percentage points higher than WOF-IOTF prevalence, the trends show a similar pattern. This suggests, as has been also noted in other studies [48-53], that more attention should be paid to the definitions used when comparing overweight/obesity among various countries around the world, though the trend analysis tends to be independent of them.

Despite the observed reduction, the overall levels of overweight and obesity in Italy remain among the highest in Europe. In fact, within the COSI initiative, Italy has high prevalence rates of overweight and obesity with levels similar to those in Greece, Spain, Portugal and Slovenia [29].

\section{Conclusions}

In Italy, from 2008 to 2016, prevalence rates of overweight and obesity among primary school children have significantly decreased. None-the-less, they are still among the highest in Europe. This implies that the number of overweight and obese children will continue to be a public health problem because quality of life and health in adulthood often depend on the habits adopted in early life. Interventions to reduce overweight and obesity and to promote healthy life styles need to be expanded and sustained and more effort should focus on children (and families) of lower social classes.

\section{Abbreviations}

BMI: Body mass index; COSI: Childhood Obesity Surveillance Initiative; IOTF: Obesity Task Force; LHU: Local Health Unit; NAFLD: Non-alcoholic fatty liver disease; WHO: World Health Organization; WOF: World Obesity Federation

\section{Acknowledgements}

The authors wish to thank the member of the Technical Committee of the National Surveillance System OKkio alla SALUTE, the 2008/9-2016 OKkio alla SALUTE groups, all the regional coordinators (list available at: https://www. epicentro.iss.it/okkioallasalute/pdf2015/Gruppi\%200Kkio\%20alla\%20SALUTE\%20. pdf) and Dr. Daniela Galeone of the Ministry of Health for their support on the implementation of the surveillance. We are grateful to Mauro Bucciarelli for his assistance with data management, to Silvia Andreozzi for her secretarial and graphic support and to Daniela Pierannunzio for her support in the last round of data collection. We also thank the Local Health Unit personnel involved in the surveys for their support in the data collection and all children, families, teachers who participated in the surveillance.

\section{Funding}

The surveys were funded by a research grant from the Italian Ministry of Health - Centre for Disease Prevention and Control, which collaborated to the design of the surveillance system, helped to get the list of schools to sample and to contact them. 


\section{Availability of data and materials}

The data that support the findings of this study are available from the Italian Ministry of Health but restrictions apply to the availability of these data, which were used under license for the current study, and so are not publicly available. Data are however available from the authors upon reasonable request and with permission of the Italian Ministry of Health.

\section{Authors' contributions}

LL made contributions to the conception of the manuscript, conducted the analyses and drafted the manuscript; AS implemented the project, made contributions to the conception of the manuscript and to the discussion of the results and critically reviewed the draft of the manuscript. MB collaborated in the coordination of the data collection, managed the database and reviewed the final manuscript. PN made contributions to the implementation of the project and the conception of the manuscript, coordinated the data collection at national level and reviewed the final manuscript. All authors contributed to and approved the final manuscript.

\section{Ethics approval and consent to participate}

Approval of the protocol was obtained from the Institutional Review Board of the National Institute of Health, including the use of opt-out consent; that is, parents were fully informed about all study procedures through a form attached to their questionnaire and the lack of a returned form was taken to imply consent to their child's participation. The child's assent was verbal.

\section{Consent for publication}

Not applicable.

\section{Competing interests}

The authors declare that they have no competing interests.

\section{Publisher's Note}

Springer Nature remains neutral with regard to jurisdictional claims in published maps and institutional affiliations.

\section{Received: 1 August 2018 Accepted: 7 May 2019}

Published online: 21 May 2019

\section{References}

1. World Health Organization. Consultation on Obesity. Obesity: preventing and managing the global epidemic. Report of a WHO consultation. World Health Organ Tech Rep Ser. 2000;894:I-xii, 1-253.

2. Ng M, Fleming T, Robinson M, Thomson B, Graetz N, Margono C, et al. Global, regional, and national prevalence of overweight and obesity in children and adults during 1980-2013: a systematic analysis for the global burden of disease study 2013. Lancet. 2014:384:766-81.

3. Lobstein T, Jackson-Leach R, Moodie ML, Hal KD, Gortmaker SL, Swinburn $\mathrm{BA}$, et al. Child and adolescent obesity: part of a bigger picture. Lancet. 2015;385:2510-20

4. NCD Risk Factor Collaboration (NCD-RisC). Worldwide trends in body-mass index, underweight, overweight, and obesity from 1975 to 2016: a pooled analysis of 2416 population-based measurement studies in 128.9 million children, adolescents, and adults. Lancet. 2017;390(10113):2627-42.

5. Ells $\sqcup$, Hancock C, Copley VR, Mead E, Dinsdale H, Kinra S, et al. Prevalence of severe childhood obesity in England: 2006-2013. Arch Dis Child. 2015;100: 631-6.

6. Skinner AC, Skelton JA. Prevalence and trends in obesity and severe obesity among children in the United States, 1999-2012. JAMA Pediatr. 2014;168: 561-6.

7. Stettler N, Zemel BS, Kumanyika S, Stallings VA. Infant weight gain and childhood overweight status in a multicenter, cohort study. Pediatrics. 2002; 109:194-9.

8. Rolland-Cachera MF, Deheeger M, Maillot M, Bellisle F. Early adiposity rebound: causes and consequences for obesity in children and adults. Int J Obes (Lond). 2006 Dec;30 Suppl 4:S11-7. Erratum in: Int J Obes (Lond). 2010;34(7):1230.

9. Whitlock G, Lewington S, Sherliker P, Clarke R, Emberson J, Halsey J, et al. Bodymass index and cause-specific mortality in 900000 adults: collaborative analyses of 57 prospective studies. Lancet. 2009;373:1083-96.
10. Park MH, Falconer C, Viner RM, Kinra S. The impact of childhood obesity on morbidity and mortality in adulthood: a systematic review. Obes Rev. 2012; 13(11):985-1000.

11. Rankin J, Matthews L, Cobley S, Han A, Sanders R, Wiltshire HD, Baker JS. Psychological consequences of childhood obesity: psychiatric comorbidity and prevention. Adolesc Health Med Ther. 2016;7:125-46.

12. Freedman DS, Mei Z, Srinivasan SR, Berenson GS, Dietz WH. Cardiovascular risk factors and excess adiposity among overweight children and adolescents: the Bogalusa heart study. J Pediatr. 2007;150(1):12-7.

13. Pulgarón ER. Childhood obesity: a review of increased risk for physical and psychological comorbidities. Clin Ther. 2013;35(1):A18-32.

14. Cunningham SA, Kramer MR, Narayan KM. Incidence of childhood obesity in the United States. N Engl J Med. 2014;370:403-11.

15. Singh AS, Mulder C, Twisk JW, van Mechelen W, Chinapaw MJ. Tracking of childhood overweight into adulthood: a systematic review of the literature. Obes Rev. 2008;9(5):474-88.

16. Wang Y, Beydoun MA. The obesity epidemic in the United States--gender, age, socioeconomic, racial/ethnic, and geographic characteristics: a systematic review and meta-regression analysis. Epidemiol Rev. 2007;29(1):6-28.

17. Haug E, Rasmussen M, Samdal O, lannotti R, Kelly C, Borraccino A, et al. Overweight in school-aged children and its relationship with demographic and lifestyle factors: results from the WHO-collaborative health behaviour in school-aged children (HBSC) study. Int J Public Health. 2009;54(Suppl 2): 167-79.

18. Claire Wang Y, Gortmaker SL, Taveras EM. Trends and racial/ethnic disparities in severe obesity among US children and adolescents, 1976-2006. Int J Pediatr Obes. 2011;6(1):12-20.

19. Popkin BM, Udry JR. Adolescent obesity increases significantly in second and third generation U.S. immigrants: the National Longitudinal Study of adolescent health. J Nutr. 1998;128(4):701-6.

20. Rossen LM, Schoendorf KC. Measuring health disparities: trends in racialethnic and socioeconomic disparities in obesity among 2- to 18-year old youth in the United States, 2001-2010. Ann Epidemiol. 2012;22(10):698-704.

21. Organisation for Economic Co-Operation and Development. OECD. Obesity Update 2017. http://www.oecd.org/health/health-systems/Obesity-Update2017.pdf. Accessed May 2018.

22. Lauria L, Spinelli A, Cairella G, Censi L, Nardone P. Buoncristiano M; 2012 group OKkio alla SALUTE. Dietary habits among children aged 8-9 years in Italy. Ann Ist Super Sanita. 2015;51(4):371-81.

23. Nardone P, Spinelli A, Lauria L, Buoncristiano M, Bucciarelli M, Galeone D, Gruppo OKkio alla SALUTE. Sociodemographic variation in childhood overweight and obesity in Italy in 2014. Epidemiol Prev. 2015;39(1):64.

24. Van Hook J, Baker E. Big boys and little girls: gender, acculturation, and weight among young children of immigrants. J Health Soc Behav. 2010; 51(2):200-14.

25. Owen CG, Martin RM, Whincup PH, Smith GD, Cook DG. Effect of infant feeding on the risk of obesity across the life course: a quantitative review of published evidence. Pediatrics. 2005;115(5):1367-77.

26. WHO European Ministerial Conference on Counteracting Obesity. Report of a WHO conference. World Health Organ 2007;1-30. http://www.euro.who. int/_data/assets/pdf_file/0006/96459/E90143.pdf. Accessed May 2018.

27. Binkin N, Fontana G, Lamberti A, Cattaneo C, Baglio G, Perra A, et al. A national survey of the prevalence of childhood overweight and obesity in Italy. Obes Rev. 2010;11:2-10.

28. Spinelli A, Baglio G, Cattaneo C, Fontana G, Lamberti A. Gruppo OKkio alla SALUTE; Coorte PROFEA anno 2006. Promotion of healthy life style and growth in primary school children (OKkio alla SALUTE). Ann lg. 2008;20:337-44.

29. Wijnhoven TM, van Raaij JM, Spinelli A, Starc G, Hassapidou M, Spiroski I, et al. WHO European childhood obesity surveillance initiative: body mass index and level of overweight among 6-9-year-old children from school year 2007/2008 to school year 2009/2010. BMC Public Health. 2014;14:806.

30. de Onis M, Onyango AW, Borghi E, Siyam A, Nishida C, Siekmann J. Development of a WHO growth reference for school-aged children and adolescents. Bull World Health Organ 2007;85:660-667. http://www.who.int/ growthref/growthref_who_bull/en/index.html . Accessed May 2018.

31. Blössner M, Siyam A, Borghi E, Onyango A, de Onis M. WHO AnthroPlus for personal computers manual: software for assessing growth of the world's children and adolescents. Geneva: World Health Organization; 2009.

32. Cole TJ, Lobstein T. Extended international (IOTF) body mass index cut-offs for thinness, overweight and obesity. Pediatr Obes. 2012;7(4):284-94. 
33. Cole TJ, Bellizzi MC, Flegal KM, Dietz WH. Establishing a standard definition for child overweight and obesity worldwide: international survey. BMJ. 2000; 320(7244):1240-3.

34. Spinelli A, Lamberti A, Baglio G, Andreozzi S, Galeone D (Ed.). OKkio alla SALUTE: sistema di sorveglianza su alimentazione e attività fisica nei bambini della scuola primaria. Risultati 2008. Roma: Istituto Superiore di Sanità; 2009. (Rapporti ISTISAN 09/24).

35. Spinelli A, Lamberti A, Nardone P, Andreozzi S, Galeone D. (Ed.). Sistema di sorveglianza OKkio alla SALUTE: risultati 2010.Roma: Istituto Superiore di Sanità; 2012. (Rapporti ISTISAN 12/14)

36. Spinelli A, Nardone P, Buoncristiano M, Lauria L, Andreozzi A, Galeone D (Ed. ). Sistema di sorveglianza OKkio alla SALUTE: dai risultati 2012 alle azioni. Roma: Istituto Superiore di Sanità; 2014. (Rapporti ISTISAN 14/11).

37. Nardone P, Spinelli A, Buoncristiano M, Lauria L, Pizzi E, Andreozzi A, et al. II Sistema di sorveglianza OKkio alla SALUTE: risultati 2014. Supplemento 1, 3(29); 2016 Notiziario Istituto Superiore di Sanità (ISSN 1827-6296).

38. Bonciani M, Nardone P, Pizzi E, Spinelli A, Andreozzi S, Giacchi M, et al (Ed.). Prevenzione dell'obesità nella scuola: indicazioni a partire dalle evidenze della letteratura. Roma: Istituto Superiore di Sanità; 2015. (Rapporti ISTISAN 15/1).

39. OKkio alla SALUTE 2016: sintesi dei risultati. http://www.salute.gov.it/imgs/ C_17_notizie_2935_listaFile_itemName_24_file.pdf. Accessed May 2018.

40. Bennet S, Woods T, Liyanage WM, Smith DL. A simplified general method for cluster-sample surveys of health in developing countries. World Health Stat Q. 1991;44:98-106

41. Censi L, Spinelli A, Roccaldo R, Bevilacqua N, Lamberti A, Angelini V, et al. Dressed or undressed? How to measure children's body weight in overweight surveillance? Public Health Nutr. 2014;17(12):2715-20.

42. JANPA-Joint Action on Nutrition and Physical Activity.The European Union's health Programme (2014-2020). A guide for programme planners and decision makers on creating healthier environments in kindergartens and schools. 2017. http://www.janpa.eu/outcomes/Deliverables/D6.3_janpa_ guide_online-Oct31.pdf. Accessed May 2018.

43. Matthiessen J, Stockmarr A, Biltoft-Jensen A, Fagt S, Zhang H, Groth MV. Trends in overweight and obesity in Danish children and adolescents: 20002008--exploring changes according to parental education. Scand J Public Health. 2014:42(4):385-92

44. Schalkwijk AAH, van der Zwaard BC, Nijpels G, Elders PJM, Platt L. The impact of greenspace and condition of the neighbourhood on child overweight. Eur J Pub Health. 2018;28(1):88-94. https://doi.org/10.1093/ eurpub/ckx037.

45. Drewnowski A, Darmon N. Food choices and diet costs: an economic analysis. J Nutr. 2005;135(4):900-4

46. Lazzeri G, Giacchi MV, Spinelli A, Pammolli A, Dalmasso P, Nardone P, et al. Overweight among students aged 11-15 years and its relationship with breakfast, area of residence and parents' education: results from the Italian HBSC 2010 cross-sectional study. Nutr J. 2014;13:69.

47. Bonati M, Campi R. What can we do to improve child health in southern Italy? PLoS Med. 2005;2(9):e250.

48. Rito A, Wijnhoven TM, Rutter H, Carvalho MA, Paixão E, Ramos C, et al. Prevalence of obesity among Portuguese children (6-8 years old) using three definition criteria: COSI Portugal, 2008. Pediatr Obes. 2012;7(6):413-22.

49. Rivera JÁ, de Cossío TG, Pedraza LS, Aburto TC, Sánchez TG, Martorell R. Childhood and adolescent overweight and obesity in Latin America: a systematic review. Lancet Diabetes \& Endocrinology. 2014;2(4):321-32.

50. Song $\mathrm{Y}$, Wang $\mathrm{H}-\mathrm{J}$, Dong $\mathrm{B}, \mathrm{Ma} J$, Wang Z, Agardh A. 25-year trends in gender disparity for obesity and overweight by using WHO and IOTF definitions among Chinese school-aged children: a multiple cross-sectional study. BMJ Open. 2016;6:e011904. https://doi.org/10.1136/bmjopen-2016-011904.

51. Monasta L, Lobstein T, Cole TJ, Vignerová J, Cattaneo A. Defining overweight and obesity in pre-school children: IOTF reference or WHO standard? Obesity Rev. 2011;12:295-300.

52. Lombardo FL, Spinelli A, Lazzeri G, Lamberti A, Mazzarella G, Nardone P, et al. Severe obesity prevalence in 8- to 9-year-old Italian children: a large population-based study. Eur J Clin Nutr. 2015;69(5):603-8.

53. Hassapidou M, Tzotzas T, Makri E, Pagkalos I, Kaklamanos I, Kapantais E, et al. Prevalence and geographic variation of abdominal obesity in 7 - and 9-yearold children in Greece; World Health Organization childhood obesity surveillance initiative 2010. BMC Public Health. 2017;17:126.

\section{Ready to submit your research? Choose BMC and benefit from:}

- fast, convenient online submission

- thorough peer review by experienced researchers in your field

- rapid publication on acceptance

- support for research data, including large and complex data types

- gold Open Access which fosters wider collaboration and increased citations

- maximum visibility for your research: over $100 \mathrm{M}$ website views per year

At BMC, research is always in progress.

Learn more biomedcentral.com/submissions 